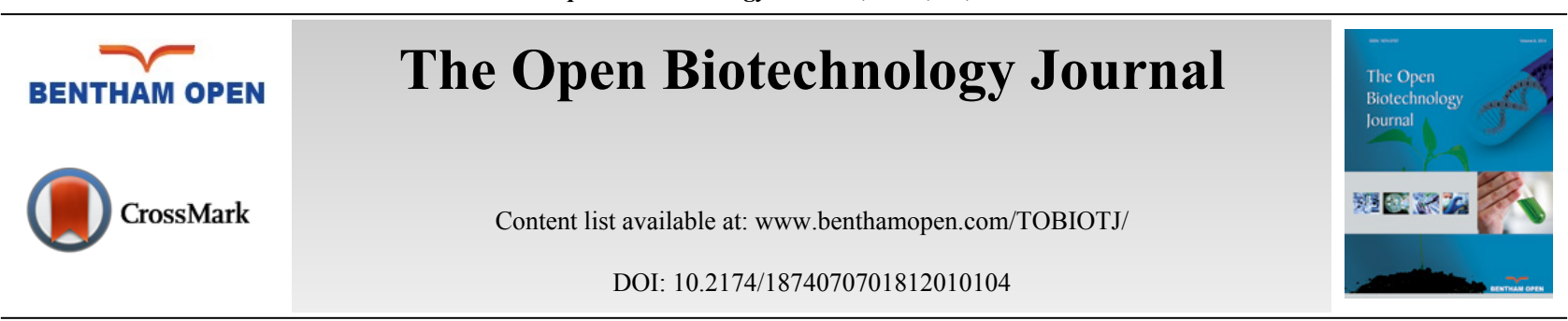

RESEARCH ARTICLE

\title{
Impact of Insect Densities Tribolium Castaneum on the Benzoquinone Secretions and Aflatoxins Levels in Wheat Flour During Storage Periods
}

\author{
Tarek A. El-Desouky ${ }^{1, *}$, Samy S. Elbadawy ${ }^{2}$, Hassan B.H. Hussain ${ }^{2}$ and Nilly A. Hassan ${ }^{2}$ \\ ${ }^{I}$ Food Toxicology and Contaminant, National Research Centre, Dokki, Giza, Egypt \\ ${ }^{2}$ Plant Protection Research Institute, Agriculture Research Center, Dokki- Giza, Egypt
}

Received: February 14, 2018

Revised: May 18, 2018

Accepted: June 7, 2018

\section{Abstract:}

\section{Objectives:}

The present study was prepared to investigate the impact of insect density, adult emergence of Tribolium castaneum on the secretion of Benzoquinones (BQs) consist of methyl-1,4-benzoquinone(MBQ) and Ethyl-1,4-Benzoquinone (EBQ), and accumulation of Aflatoxins (AFs) in wheat flour stored at different periods.

\section{Methods:}

Forty grams of wheat flour were put into small glass jars $(8 \mathrm{~cm}$ diameter and $12 \mathrm{~cm}$ length). Then $T$. castaneum was put in each jars at rates of 10, 20 and 30 unsexed pairs of insect adult. The jars were covered with muslin cloth and the rubber band was fixed to prevent insects to escape. A glass jar without any insects served as the control. The jars lifted on bench in the laboratory for two, three and four months of storage under laboratory temperature conditions (with average $28 \pm 2 \mathrm{C}$ and $65 \pm 5 \mathrm{R} . \mathrm{H}$ ). The previous design was replicated three times. At the end of each storage period, the jars containing the flour were sieved thoroughly by 40 wire mesh size to separate the insects. The insects have been counted on the other hand wheat flour was prepared to determine MBQ, EBQ and AFs by HPLC methods.

\section{Results:}

The results indicated the levels of EBQ higher than MBQ in all infested samples at all insect densities (No. of insect pairs). The concentrations of MBQ in wheat flour released by ten adult pairs (10P) with the three storage periods two, three and four months were $10.42 \pm 0.56,22.38 \pm 3.67,27.06 \pm 6.71 \mu \mathrm{g} / \mathrm{g}$, respectively. These results increased with insect densities to (30p) were $39.67 \pm$ $0.10,63.58 \pm 2.35$ and $106.24 \pm 7.4 \mu \mathrm{g} / \mathrm{g}$ after storage periods two, three and four months, respectively. In addition to the concentrations of EBQ with (10P) were $67.45 \pm 3.64,98.0 \pm 6.1204 .66 \pm 5.8 \mu \mathrm{g} / \mathrm{g}$ with storage periods two, three and four months, respectively. In case (30P) the levels of EBQ were $376.7 \pm 0.87,570.1 \pm 2.11$ and $1558.66 \pm 10.88(\mu \mathrm{g} / \mathrm{g})$. The highest concentration of the BQs $1664.90 \pm 11.43(\mu \mathrm{g} / \mathrm{g})$ released by T. castaneum achieved with the highest adult emergence (1021 insect adult) and the highest insect density (30p) at four months storage period. In general, AFs levels enhanced with a period of storage and insect densities.

\section{Conclusion:}

Levels of the BQs (MBQ and EBQ) increased with an increase of storage periods and insect densities. Therefore, the presence of this insect should be prevented in stored wheat flour reducing AFs contamination is possible by storage for short time and prohibit insects which causes an increase temperature of the flour and moisture, all of which promote production of AFs.

\footnotetext{
* Address correspondence to this author at the Toxicology and Contaminant, National Research Centre, Dokki, Giza, Egypt; Tel: +201098635889; E-mail: eldesoukyt@yahoo.com
} 
Keywords: Tribolium castaneum, Benzoquinone, Aflatoxins, Wheat flour, Insect densities, Storage Period, Contamination.

\section{INTRODUCTION}

The wheat flour is subjected to attack by many flour beetles, including the red flour beetle (Tribolium castaneum). The red flour beetle, T. castaneum is a polyphagous, cosmopolitan pest in flour mills and wherever cereal products and other dried foods were processed and/or stored. It is often the most common species in the pest complex attacking stored wheat. Mature flour beetles infect and/or contaminate the flour and give unpleasant odor and pinkish color [1], this negatively affects certain characteristics, such as viscous and elastic properties of the flour and create a disgusting taste. Some of the beetles have the ability to produce Benzoquinones (BQs) from specialized prothoracic and post abdominal glands. The chemical structures of the major components of these beetles secretions have been shown to consist of Methyl-1,4-Benzoquinone(MBQ) and Ethyl-1,4-Benzoquinone (EBQ), together with the carrier alkene 1pentadecene. These compounds are hypothesized to function as external defense compounds, killing microbes and deterring predators, and their ability to evolve by natural selection depends on both selection and the genetic vs. environmental contribution to phenotypic variation $[2,3]$. Many studies indicated that BQs produced or secreted by flour beetles may have toxic and carcinogenic effects on human and experimental animals [4 - 6]. Infestation of grains and stored products by insects promote growth of fungi including those that produce mycotoxins such as Aflatoxins (AFs) and results in contamination of commodities with insect bodies and waste products etc. Some of which are toxic, repulsive or allergenic [7]. AFs are group of secondary metabolites and highly carcinogenic produces by A. flavus and A. parasiticus. The four types major naturally produced known as Aflatoxin $\mathrm{B}_{1}\left(\mathrm{AFB}_{1}\right)$, Aflatoxin $\mathrm{B}_{2}\left(\mathrm{AFB}_{2}\right)$, Aflatoxin $\mathrm{G}_{1}\left(\mathrm{AFG}_{1}\right)$, and Aflatoxin $\mathrm{G}_{2}\left(\mathrm{AFG}_{2}\right)$. B and $\mathrm{G}$ refer to the blue and green fluorescent colors under UV light on Thin Layer Chromatography plates, while the subscript numbers related to their relative chromatographic mobility $[8,9]$. Also (AFs) produced by A. nomius, A. bombycis, and A. pseudotamarii [10 - 13]. The insect also plays a significant role in the dissemination and proliferation of microorganisms including mycotoxigenic fungi in food commodities [14]. This work aims to study the effect of density of $T$. castaneum on the secretion of BQs and accumulation of AFs in wheat flour stored at different periods.

\section{MATERIALS AND METHODS}

\subsection{Insect Cultures}

The stock of insect used in this experiments (T. castaneum) was collected from stock culture maintained at stored grain and product pests Department, Plant Protection Research Institute, Agriculture Research Center, whereas they are reared at $28 \pm 2 \mathrm{C}$ and $65 \pm 5$ R.H. on whole wheat flour for two months.

\subsection{Experimental Procedures}

Forty grams of wheat flour were put into small glass jars $(8 \mathrm{~cm}$ diameter and $12 \mathrm{~cm}$ length). Then T. castaneum was put into each jars at rates of 10,20 and 30 unsexed pairs of insect adult. The jars were covered with muslin cloth and the rubber band was fixed to prevent insects to escape. A glass jar without any insects served as the control

The jars were left on bench in the laboratory for two, three and four months of storage under laboratory temperature conditions (with average $28 \pm 2 \mathrm{C}$ and $65 \pm 5$ R.H). The previous design was replicated three times. At the end of each storage period, the jars containing the flour were sieved thoroughly by 40 wire mesh size to separate the insects. The insects have been counted on the other hand, the wheat flour was prepared for determination of MBQ, EBQ and AFs by HPLC methods.

\subsection{Extraction and Determination of BQs and AFs Using HPLC}

BQs were extracted and determined according to Tomoskozi-Farkas and Daood method [15]. While AFs extracted and determined according to AOAC [16]

\section{RESULTS AND DISCUSSION}

\subsection{Levels of BQs (MBQ and EBQ) in Wheat Flour Samples}

Data represented in Table 1 showed the levels of MBQ and EBQ in samples wheat flour infested by T. castaneum at different storage period. The levels of MBQ during four month were 59.86 $\pm 10.94,123.52 \pm 11.57$ and $209.49 \pm 9.87$ 
with 10P, 20P and 30P, respectively. While the level of EBQ in samples were 370.11 $\pm 15.6,1498.25 \pm 12.5$ and $2505.46 \pm 13.88$ with $10 \mathrm{P}, 20 \mathrm{P}$ and 30P, respectively. The results indicated that the levels of EBQ higher than MBQ in all infested samples at all insect densities (No. of insect pairs) and storage periods.

Table 1. Levels of BQs in wheat flour samples infested by $T$. castaneum at different storage periods.

\begin{tabular}{|c|c|c|c|c|c|c|c|}
\hline \multirow{3}{*}{ Storage Periods } & \multicolumn{7}{|c|}{ Concentrations of BQs $(\mu \mathrm{g} / \mathrm{g})^{*}$} \\
\hline & \multicolumn{4}{|c|}{ MBQ } & \multicolumn{3}{|c|}{ EBQ } \\
\hline & Control & $10 \mathrm{P}$ & $20 P$ & 30P & $10 \mathrm{P}$ & $20 \mathrm{P}$ & $30 \mathrm{P}$ \\
\hline Two Months & \multirow{5}{*}{ ND } & $10.42 \pm 0.56$ & $28.56 \pm 3.7$ & $39.67 \pm .1 .1$ & $67.45 \pm 3.64$ & $199.5 \pm 2.6$ & $376.7 \pm 0.87$ \\
\hline Three Months & & $22.38 \pm 3.67$ & $40.26 \pm 4.26$ & $63.58 \pm 2.35$ & $98.0 \pm 6.1$ & $355.5 \pm 3.77$ & $570.1 \pm 2.11$ \\
\hline Four Months & & $27.06 \pm 6.7$ & $54.7 \pm 3.6$ & $106.24 \pm 7.4$ & $204.66 \pm 5.85$ & $943.2 \pm 6.2$ & $1558.66 \pm 10.88$ \\
\hline Total during storage & & \begin{tabular}{|l|}
$59.86 \pm 10.94$ \\
\end{tabular} & $123.52 \pm 11.57$ & $209.49 \pm 9.87$ & $370.11 \pm 15.6$ & $1498.25 \pm 12.5$ & $2505.46 \pm 13.88$ \\
\hline BQs ( $\mu \mathrm{g} /$ insect) & & 2.99 & 6.2 & 10.47 & 18.51 & 74.9 & 125.3 \\
\hline
\end{tabular}

*mean \pm SD ND $=$ Not detected; $\mathrm{P}=$ Pair of insect

These results agree with [17] found that the Quinone consists of 80 to $90 \%$ ethylquinone; 10 to 20 methyl quinone with a trace of other components. As well as Markarian et al [18] obtained 37\% MBQ and 63\% EHQ in the secretion of T. castaneum. These odorous BQs from Tribolium spp. have been well documented previously [19, 20]. Hodges et al. [21] did not found significant accumulations of quinones from beetles in dehusked rice, but contaminated wheat flour showed a more serious problem and the same two benzoquinone derivatives were reported and considered to be the secretions of T. castaneum.

\subsection{Relationship between Insect Density of T. Castaneum and Levels of BQs Secretion}

Data presented in Table 1 show increased levels of BQs (MBQ and EBQ) with an increase of the T. castaneum insect densities. The concentrations of MBQ in wheat flour released by ten adult pairs (10P) with the three storage periods two, three and four months were $10.42 \pm 0.56,22.38 \pm 3.67,27.06 \pm 6.71 \mu \mathrm{g} / \mathrm{g}$, respectively. The result indicated that concentrations of MBQ increased with insect densities in case 30 adult pairs (30p) were $39.67 \pm 0.10$, $63.58 \pm 2.35$ and $106.24 \pm 7.4(\mu \mathrm{g} / \mathrm{g})$ after storage periods two, three and four months, respectively. In addition to the concentrations of EBQ with (10P) were $67.45 \pm 3.64,98.0 \pm 6.1204 .66 \pm 5.8 \mu \mathrm{g} / \mathrm{g}$ with storage periods two, three and four months, respectively. In case (30P) the levels of EBQ were $376.7 \pm 0.87,570.1 \pm 2.11$ and $1558.66 \pm 10.88(\mu \mathrm{g} / \mathrm{g})$ at two, three and four months, respectively. In general, the total secretion rate of the two benzoquinones was increased with increasing of No. of pairs (insect density) of T. castaneum at the three storage periods. Senthilkumar et al. [22] found that the amount of volatiles produced by T. castaneum adults in wheat flour samples were a direct relationship which increased with an increase in insect density. The concentration of MBQ, EBQ and 1 tridecene released by ten adult insect were: $8.5,9.1$ and $10.6 \mu \mathrm{g} / 100 \mu \mathrm{l}$ compared to 7,8 and $4.2 \mu \mathrm{g} / 100 \mu \mathrm{l}$ for five adult insects after $72 \mathrm{~h}$ storage period.

Results shown in Table 1 appeared that the concentrations of MBQ per insect were 2.99, 6.2 and 10.47 ( $\mu \mathrm{g} / \mathrm{insect})$ with 10P, 20P and 30P, respectively. In the same condition the concentrations of EBQ were 18.51, 74.9 and 125.25 $\mu \mathrm{g} /$ insect with the three insect densities (10p, 20p and 30p, respectively). These results agree with Unruh et al. [23] who reported that, in $T$. castaneum samples of newly eclosed adults, levels of MBQ and EBQ were very low, $\geq 0.1$ and $\geq 0.3$ $\mu \mathrm{g}$ per insect, respectively. The quinones increased with over time approximately to 40 - 50 days posteclosion. Where, the average total concentration of all quinones at 40 days posteclosion was $45 \mu \mathrm{g} /$ insect, and the levels were as follows $18 \mu \mathrm{g}$ MBQ and 27 EBQ per insect. On the other hand, after 80 days, the amount of quinone was not significantly different from the overall total for a day with 40 beetles. Accumulation of quinones in flour wheat was probably due to an extended survival of the presence of the beetles in flour. However, the level of quinones changes from 9.2 to $472 \mu \mathrm{g} / \mathrm{g}$ according on the species of flour beetles and storage periods [24, 25$]$.

\subsection{Effect of T. Castaneum Adult Emergence on BQs (Sum both of MBQ and EBQ) Secretion}

Data illustrated in Table 2 showed that the secretion of BQs by T. castaneum adults increased with an increase in adult emergence with the three insect densities and storage periods. The highest concentration of the BQs $1664.90 \pm 11.43(\mu \mathrm{g} / \mathrm{g})$ released by $T$. castaneum achieved with the highest adult emergency (1021 insect adult) and the highest insect density (30p) at four months storage period, while, the lowest concentration level $77.87 \pm 4.21$ ( $\mu \mathrm{g} / \mathrm{g}$ ) was recorded with the lowest insect density (10p) and adult emergency (550 adult) at the two months storage period. Also, in Table 2, the other concentration values of the BQs were increased with the increasing of adult emergence with the 
analogous insect densities and storage periods. These results are in agreement with Mondal [26] they showed that; levels of the quinones were low in newly emerged adults $(<20 \mu \mathrm{g}$ per insect). While with age until 20 to 30 days after adult emergence the level of benzoquinones were increased. The levels were maintained for a long time after that time. In addition, females have higher levels of BQs than males of the same age.

Table 2. Effect of emerged adults on BQs and accumulation of total AFs in infested wheat flour by $T$. castaneum at different storage periods.

\begin{tabular}{|c|c|c|c|c|c|c|c|c|c|}
\hline \multirow{3}{*}{$\begin{array}{l}\text { Insect } \\
\text { Density }\end{array}$} & \multicolumn{9}{|c|}{ Storage Periods } \\
\hline & \multicolumn{3}{|c|}{2 Months } & \multicolumn{3}{|c|}{3 Months } & \multicolumn{3}{|c|}{4 Months } \\
\hline & A.C.No of insect & BQs $(\mu \mathrm{g} / \mathrm{g})$ & $\begin{array}{c}\mathrm{AFs} \\
(\boldsymbol{\mu \mathrm { g } / \mathrm { kg } )}\end{array}$ & A.C.No of insect & BQs $(\mu \mathrm{g} / \mathrm{g})$ & $\begin{array}{c}\mathrm{AFs} \\
(\mu \mathrm{g} / \mathrm{kg})\end{array}$ & A.C.No of insect & BQs $(\mu \mathrm{g} / \mathrm{g})$ & AFs $(\mu \mathrm{g} / \mathrm{kg})$ \\
\hline Control & 0.0 & ND & ND & 0.0 & ND & $0.217 \pm 0.03$ & 0.0 & ND & $0.75 \pm 0.09$ \\
\hline $10 p$ & $550.0 \pm 2.97$ & $77.87 \pm 4.21$ & $1.29 \pm 0.07$ & $519.3 \pm 3.6$ & $120.38 \pm 1.97$ & $4.5 \pm 0.74$ & $629.0 \pm 12.3$ & $231.72 \pm 4.54$ & $4.85 \pm 1 . .2$ \\
\hline $20 p$ & $663.0 \pm 8.63$ & $228.1 \pm 2.9$ & $3.31 \pm 0.43$ & $918.4 \pm 4.74$ & $385.68 \pm 4.09$ & $3.54 \pm 0.37$ & $958.33 \pm 6.29$ & $997.9 \pm 6.55$ & $4.4 \pm 0.3$ \\
\hline $30 p$ & $761.0 \pm 1.41$ & $416.37 \pm 5.2$ & $4.05 \pm 0.01$ & $998.3 \pm 3.63$ & $633.7 \pm 2.34$ & $5.14 \pm 0.19$ & $1021.0 \pm 7.01$ & $1664.9 \pm 11.43$ & $5.38 \pm 0.37$ \\
\hline
\end{tabular}

A.C.No=Adults cumulative number $=$ Emerged adults; $\mathrm{ND}=$ Not detected

There are many interpretations to explain the low secretions of quinones from flour beetles with newly emerged Tribolium adults and then increased with increase of storage period time. Wirtz et al. [27] proposition that shortage of defensive secretion in newly emerged Tribolium adults reflects the need for an adequate barrier for self-protection. Only after that time does a rapid build-up of BQs occurs in adults. In another study, Mondal [26] did not show the detection secretion of the quinones in larvae or in prepupae, but quinones may be detected in some very late pupae and after one hour in adults emergence. There are many ways for quinones to enter into the flour, a great number of deaths of insects in a culture both in the laboratory and in the storehouse may lead to the extent of quinones in the flour medium [28]. Emptying of quinones is under some conditions such as crowding, excitement [1], agitation of the beetles [28] and partial narcosis [29]. The Tribolium spp. beetles outcome in the wheat flour becomes contaminated with quinone secretions thus, these quinone secretions may reduce the population of flour beetles. Fortunately, quinone secretion is highly toxic to the flour beetles themselves. In addition, Quinone secretion is able to producing different abnormalities in flour beetle populations; the effect varies with the developmental stages of the insects. Quinones cause reduced fecundity and fertility to Tribolium, therefore lessening of the reproductive rate [30]. On other hand, Happ [31] showed that tenebrionids are somewhat protected from their own secretions, within Tribolium species, this self-protection is evident in the partitioning of the secretion away from cells, first in the cuticle-lined organelles where the secretion is produced.

Previous studies indicate that BQs produced by flour beetles infesting the flour or grains may have a toxic effect on humans and animals was direct or indirect. Quinones can make infested flour unsuitable for human consumption and, flour may reach the point where it becomes toxic. Quinones are acutely toxic and allergenic as well as carcinogenic to human beings $[5,32,33]$.

El-Mofty et al. [4, 6, 34] reported that, baking temperature did not reduce the carcinogenic effect of biscuits made from flour infested with $T$. castaneum beetles but the mutagenic effects on mice remains unclear after being contaminated flour had been cooked and consumed, and Tribolium spp. are the only storage pests producing carcinogenic and teratogenic contaminants. These compounds give an unpleasant smell to stored food and may be responsible for liver and spleen tumors in small vertebrates as well as bread prepared made from flour infested by Tribolium spp had a bad taste [35].

\subsection{Effect of Storage Periods and Insect Density of T. Castaneum on AFs Levels.}

Data illustrated in Table 3 showed that, there are relationships between storage periods and insect densities (10p, $20 \mathrm{p}$ and 30p) with foundation of AFs. We found significant relationship between the levels of $\mathrm{AFG}_{1}, \mathrm{AFB}_{1}, \mathrm{AFG}_{2}$ and $\mathrm{AFB}_{2}$ and total AFs with the insect densities and storage periods. The results revealed that generally, AFs levels increased with the period of storage and insect densities. Four-month stored infested flour sample had the highest total concentration of Aflatoxin $\left(\mathrm{AFG}_{1}, \mathrm{AFB}_{1}, \mathrm{AFG}_{2}\right.$ and $\left.\mathrm{AFB}_{2}\right)$ with $4.85,4.40$ and $5.38 \mu \mathrm{g} / \mathrm{kg}$, respectively with the insect densities (10p, 20p and 30p). Aflatoxin concentration levels of the two months storage period were 1.29 $\pm 0.7,3.31 \pm 0.43$ and $4.06 \pm 0.2 \mu \mathrm{g} / \mathrm{kg}$, respectively, while, total AFs of the three months storage period were 4.5 $\pm 0.74,3.54 \pm 0.37$ and $5.14 \pm 0.2 \mu \mathrm{g} / \mathrm{kg}$, respectively. However, $\mathrm{AFG}_{1}$ and $\mathrm{AFB}_{2}$ more had in concentrations than $\mathrm{AFB}_{1}$ and $\mathrm{AFG}_{2}$ in the stored 
flour samples. Furthermore, total AFs increased with increasing of insect density with the exception that insect density $20 \mathrm{p}$ was decreasing at the three and four storage month's periods. These results confirmed by Jonathan, et al. [36] who reported that, aflatoxin levels increased with the period of storage. Eighteen-month stored flour sample had the highest concentration of $\mathrm{AFB}_{1}, \mathrm{AFB}_{2}, \mathrm{AFG}_{1}$ and $\mathrm{AFG}_{2}$ with $0.0033 \mu \mathrm{g} / \mathrm{kg}, 0.0085 \mu \mathrm{g} / \mathrm{kg}, 0.0080 \mu \mathrm{g} / \mathrm{kg}$ and $0.0065 \mu \mathrm{g} / \mathrm{kg}$, respectively and generally, $\mathrm{AFB}_{2}$ and $\mathrm{G}_{1}$ had more concentrations than $\mathrm{AFG}_{1}$ and $\mathrm{G}_{2}$ in the stored samples.

Table 3. Concentration of AFs in infested wheat flour by T. castaneum with different storage periods.

\begin{tabular}{|c|c|c|c|c|c|c|c|c|c|c|c|c|}
\hline \multirow{2}{*}{$\operatorname{AFs}(\mu \mathrm{g} / \mathrm{kg})$} & \multicolumn{4}{|c|}{2 Months } & \multicolumn{4}{|c|}{3 Months } & \multicolumn{4}{|c|}{4 Months } \\
\hline & Control & 10p & $20 p$ & 30p & control & $10 p$ & $20 p$ & $30 p$ & control & $10 p$ & $20 p$ & $30 p$ \\
\hline $\mathbf{A F G}_{1}$ & \multirow{5}{*}{ ND } & ND & $0.963 \pm 0.13$ & $3.7 \pm 0.01$ & $0.217 \pm 0.03$ & $3.78 \pm .62$ & $0.88 \pm .1$ & $1.74 \pm 0.06$ & $0.33 \pm 0.04$ & $3.88 \pm 0.96$ & $0.85 \pm 0.06$ & $1.72 \pm 0.12$ \\
\hline $\mathbf{A F B}_{1}$ & & $1.29 \pm 0.07$ & $0.169 \pm 0.02$ & $\mathrm{ND}$ & $\mathrm{ND}$ & $\mathrm{ND}$ & $0.58 \pm .06$ & $0.85 \pm .04$ & $0.18 \pm 0.02$ & $0.23 \pm 0.06$ & $1.21 \pm 0.08$ & $0.84 \pm 0.07$ \\
\hline$\overline{\mathrm{AFG}_{2}}$ & & \begin{tabular}{|l|} 
ND \\
\end{tabular} & ND & $0.36 \pm 0.01$ & $\mathrm{ND}$ & $0.72 \pm .12$ & $\mathrm{ND}$ & $\mathrm{ND}$ & $0.25 \pm 0.03$ & $0.74 \pm 0.18$ & $\mathrm{ND}$ & ND \\
\hline $\mathbf{A F B}_{2}$ & & ND & $2.18 \pm 0.28$ & $\mathrm{ND}$ & ND & ND & $2.08 \pm 0.22$ & $2.57 \pm 0.1$ & $\mathrm{ND}$ & ND & $2.34 \pm 0.15$ & $2.77 \pm 0.19$ \\
\hline Total AFs & & $1.29 \pm 0.07$ & $3.31 \pm 0.43$ & $4.05 \pm 0.01$ & $0.217 \pm 0.03$ & $4.5 \pm 0.74$ & $3.54 \pm 0.37$ & $5.14 \pm 0.19$ & $0.75 \pm 0.09$ & $4.85 \pm 1.2$ & \begin{tabular}{|l|}
$4.4 \pm 0.3$ \\
\end{tabular} & $5.38 \pm 0.38$ \\
\hline
\end{tabular}

$\mathrm{ND}=$ Not detected

Among fungal toxins, which have been noticed in several studies, AFs are a large group of mycotoxins which are produced by some species of Aspergillus spp on foods such as cereals including (wheat, corn and barley) as well as legume, nuts and feed. These species have a worldwide prevalence. Diseases in animals and human by AFs called aflatoxicosis. Acute aflatoxicosis, associated with extremely high doses of AFs, is characterized by hemorrhage, acute liver damage, edema, and death in humans. Conditions increasing the likelihood of acute aflatoxicosis in humans include limited availability of food, environmental conditions that favor fungal development in crops and commodities, and lack of regulatory systems for AFs monitoring and control. On the other hand, these fungal contaminations not only pose a serious health risk to consumers but also diminish the nutritional value and economic benefits of the food. Wheat contamination with fungi and AFs has been noted in several studies, the presence of high levels of aflatoxins in stored foods may made it unacceptable for marketing, causing financial loss to the farmers or retailers [37, 38]. The maximum level of AFs cereal, wheat flour and cereal products according to European Union (EU) and Egyptian Standard (ES) were 4 and $2 \mu \mathrm{g} / \mathrm{kg}$. Accordingly, five samples exceeded the maximum set in the EU and ES. Cereals and other crops are exposed to fungal attack in the field (pre-harvest) or during storage and this would result in the production of AFs. Also the climatic and storage conditions practices also play important role in fungal attack and mycotoxins production. Due to improper storage conditions in urban areas of Egypt. It also has been reported that increased AFs formation was registered by heavy rains during the storage, by delayed storage and high moisture contents [39, 40]. Tirado et al. [41] reported that the AFs are expected to become more prevalent with climate change in countries with temperate climate which has not with this problem before.

\section{CONCLUSION}

Stored wheat flour should be inspected frequently at a regular interval to detect whether they have been infested by flour beetles through the presence of quinones in flour by HPLC analysis. Consequently, these benzoquinone compounds which were produced by adults might be used as biomarkers for detection of T. castaneum in flour or grain. The results of this study indicate that the levels of the BQs (MBQ and EBQ) increased with an increase of storage periods and insect densities. Therefore, the presence of this insect should be prevented in stored wheat flour. In this study, reducing AFs contamination is possible by reducing wheat flour storage time, humidity and insects, causing an increase in temperature of the flour and moisture, all of which promote the production of AFs.

\section{ETHICS APPROVAL AND CONSENT TO PARTICIPATE}

Not applicable.

\section{HUMAN AND ANIMAL RIGHTS}

No animals/humans were used for studies that are the basis of this research. 


\section{CONSENT FOR PUBLICATION}

Not applicable.

\section{CONFLICT OF INTEREST}

The authors declare no conflict of interest, financial or otherwise.

\section{ACKNOWLEDGEMENTS}

Declared none.

\section{REFERENCES}

[1] Engelhardt M, Rapoport H, Sokoloff A. Odorous secretion of normal and mutant Tribolium confusum. Science 1965; 150(3696): 632-3. [http://dx.doi.org/10.1126/science.150.3696.632] [PMID: 5837106]

[2] Ruther J, Reinecke A, Tolasch T, Hilker M. Make love not war: A common arthropod defence compound as sex pheromone in the forest cockchafer Melolontha hippocastani. Oecologia 2001; 128(1): 44-7. [http://dx.doi.org/10.1007/s004420100634] [PMID: 28547088]

[3] Yezerski A, Gilmor TP, Stevens L. Genetic analysis of benzoquinone production in Tribolium confusum. J Chem Ecol 2004; 30(5): 1035-44. [http://dx.doi.org/10.1023/B:JOEC.0000028465.37658.ae] [PMID: 15274446]

[4] El-Mofty MM, Sakr SA, Osman SI, Toulan BA. Carcinogenic effect of biscuits made of flour infested with Tribolium castaneum in Bufo regularis. Oncology 1989; 46(1): 63-5. [http://dx.doi.org/10.1159/000226684] [PMID: 2915895]

[5] El-Mofty MM, Khudoley VV, Sakr SA, Fathala NG. Flour infested with Tribolium castaneum, biscuits made of this flour, and 1,4benzoquinone induce neoplastic lesions in Swiss albino mice. Nutr Cancer 1992; 17(1): 97-104. [http://dx.doi.org/10.1080/01635589209514176] [PMID: 1574448]

[6] El-hassaneen YA, El-Mofty AA. Abd. Blood oxidant and antioxidant status in rats feeding with insect-infested wheat flour. Pak J Biol Sci 2003; 6: 1354-60. [http://dx.doi.org/10.3923/pjbs.2003.1354.1360]

[7] Freeman JA. Problems of stored-products entomology in Britain arising out of the import of tropical products. Ann Appl Biol 1976; 84: $120-4$. [http://dx.doi.org/10.1111/j.1744-7348.1976.tb01740.x]

[8] El-Desouky TA, Amer MM, Naguib K. Effect of fenugreek seeds extracts on growth of aflatoxigenic fungus and aflatoxin $\mathrm{B}_{1}$ production. $\mathrm{J}$ Appl Sci Res 2013; 9(7): 4418-25.

[9] Siciliano I, Dal Bello B, Zeppa G, Spadaro D, Gullino ML. Static hot air and infrared rays roasting are efficient methods for aflatoxin decontamination on hazelnuts. Toxins (Basel) 2017; 9(2): 72. [http://dx.doi.org/10.3390/toxins9020072] [PMID: 28230792]

[10] Kurtzman CP, Horn BW, Hesseltine CW. Aspergillus nomius, a new aflatoxin-producing species related to Aspergillus flavus and Aspergillus tamarii. Antonie van Leeuwenhoek 1987; 53(3): 147-58. [http://dx.doi.org/10.1007/BF00393843] [PMID: 3116923]

[11] Payne GA. Process of contamination by aflatoxin-producing fungi and their impact on crops. In: Sinha KK, Bhatnager D (eds) Mycotoxins in Agriculture and Food Safety. Marcel Dekker, New York,1998; pp 279-306.

[12] Ito Y, Peterson SW, Wicklow DT, Goto T. Aspergillus pseudotamarii, a new aflatoxin producing species in Aspergillussection Flavi. Mycol Res 2001; 105: 233-9. [http://dx.doi.org/10.1017/S0953756200003385]

[13] Peterson SW, Ito Y, Horn BW, Goto T. Aspergillus bombycis, a new aflatoxigenic species and genetic variation in its sibling species, A. nomius. Mycologia 2001; 689-703. [http://dx.doi.org/10.2307/3761823]

[14] Weston PA, Rattlingourd PL. Progeny production by Tribolium castaneum (Coleoptera: Tenebrionidae) and Oryzaephilus surinamensis (Coleoptera: Silvanidae) on maize previously infested by Sitotroga cerealella (Lepidoptera: Gelechiidae). J Econ Entomol 2000; 93(2): 533-6. [http://dx.doi.org/10.1603/0022-0493-93.2.533] [PMID: 10826210]

[15] Tomoskozi-Farkas R, Daood HG. Modification of chromatographic method for the determination of benzoquinones in cereal products. Chromatographia 2004; 60: 227-30. [http://dx.doi.org/10.1365/s10337-004-0201-4] 
[16] A.O.A.C. Association of Official Analytical Chemists. Official Methods of Analysis of AOAC. International 17 ${ }^{\text {th }}$ ed. Arlington, Virginia, USA: Nature Toxins 2000.

[17] Loconti JD, Roth LM. Composition of the odorous secretion of Tribolium castaneum. Ann Entomol Soc Am 1953; 46: 281-9. [http://dx.doi.org/10.1093/aesa/46.2.281]

[18] Markarian H, Florentine GJ, Pratt JJ. Quinone production of some species of Tribolium. J Insect Physiol 1978; 24: 785-90. [http://dx.doi.org/10.1016/0022-1910(78)90096-3]

[19] Pappas PW, Wardrop SM. Quantification of benzoquinones in the flour beetles. Tribolium castaneum and Tribolium confusum. Prep Biochem Biotechnol 1996; 26(1): 53-66.

[http://dx.doi.org/10.1080/10826069608000050] [PMID: 8744422]

[20] Villaverde ML, Juarez MP, Mijailovsky S. Detection of Tribolium castaneum (Herbst) volatile defensive secretions by Solid Phase Microextraction-Capillary Gas Chromatography (SPME-CGC). J Stored Prod Res 2007; 43: 540-5. [http://dx.doi.org/10.1016/j.jspr.2007.03.003]

[21] Hodges RJ, Robinson R, Hall DR. Quinone contamination of dehusked rice by Tribolium castaneum (Herbst) (Coleoptera: Tenebrionidae). J Stored Prod Res 1995; 32: 31-7. [http://dx.doi.org/10.1016/0022-474X(95)00036-7]

[22] Senthilkumar T, Jayas DS, White NDG, Freund MS, Shafai C, Thomson DJ. Characterization of volatile organic compounds released by granivorous insects in stored wheat. J Stored Prod Res 2012; 48: 91-6. [http://dx.doi.org/10.1016/j.jspr.2011.09.006]

[23] Unruh LM, Xu R, Karl J. Kramer. Benzoquinone levels as a function of age and gender of the red flour beetle, Tribolium castaneum. Insect Biochem Mol Biol 1998; 28: 969-77. [http://dx.doi.org/10.1016/S0965-1748(98)00085-X]

[24] Mondal KAMSH. Response of Tribolium castaneum (Herbst) larvae to the different components of conditioned medium. Tribolium Information Bulletin 1983; 23: 104-11.

[25] Mondal KAMSH. Response of Tribolium castaneum larvae to aggregation pheromone and quinones produced by adult conspecifics. Int Pest Control 1985; 27: 64-6.

[26] Mondal KAMSH. Quinone secretions of flour beetles, Tribolium problems and prospects. Tribolium Inf. Bull, California Univ 1992 No. 32 , $79-89$.

[27] Wirtz RA, Taylor SL, Semey HG. Concentrations of substituted r-benzoquinones and 1-pentadecene in the flour beetles Tribolium madens (Charp.) and T. brevicornis (Lec.) (Coleoptera, Tenebrionidae). Comp Biochem Physiol 1978; 61C: 287-90.

[28] Ogden JC. Effects of components of conditioned medium on behaviour of Tribolium confusum. Physiol Zool 1969; 42: 266-74 [http://dx.doi.org/10.1086/physzool.42.3.30155490]

[29] Irwin DG, Smith LW, Pratt JJ Jr. Effects of carbon dioxide and nitrogen on the secretion of parabenzoquinones by Tribolium castaneum Herbst. J Stored Prod Res 1972; 8: 213-9. [http://dx.doi.org/10.1016/0022-474X(72)90042-2]

[30] Joop G, Roth O, Schmid-Hempel P, Kurtz J. Experimental evolution of external immune defences in the red flour beetle. J Evol Biol 2014; 27(8): 1562-71. [http://dx.doi.org/10.1111/jeb.12406] [PMID: 24835532]

[31] Happ GM. Quinone and hydrocarbon production in the defensive glands of Eleodes longicollis and Tribolium castaneum (Coleoptera, Tenobrionidae). J Insect Physiol 1968; 14: 1821-37. [http://dx.doi.org/10.1016/0022-1910(68)90214-X]

[32] Phillips JK, Burkholder WE. Heath hazards of insects and mites in food. In: Baur, F. J. (Ed), Insect Management for Food Storage and Processing. Amercian Association of Cereal Chemists, St. Paul, MN. pp.280-292

[33] Ladisch RK, Ladisch SK, Howe PM. Quinoid secretions in grain and flour beetles. Nature 1967; 215(5104): 939-40. [http://dx.doi.org/10.1038/215939a0] [PMID: 6055420]

[34] el-Mofty MM, Osman SI, Sakr SA, Toulan BA. Carcinogenicity of flour infested with Tribolium castaneum using the Egyptian toad Bufo regularis as a biological test animal. Oncology 1988; 45(1): 65-7. [http://dx.doi.org/10.1159/000226533] [PMID: 3340395]

[35] Smith LW, Pratt JJ, Nii I, Umina AP. Baking and taste properties of bread made from hard wheat flour infested with species of Tribolium, Tenebrio, Trogoderma, and Oryzaephilus. J Stored Prod Res 1971; 6: 307-16. [http://dx.doi.org/10.1016/0022-474X(71)90043-9]

[36] Jonathan SG. Abdul-Lateef MB and Ayansina ADV. Fungal and aflatoxin detection in fresh and stored 'Garri Ijebu' (locally processed food). Rep Opinion 2013; 5(2): 13-9.

[37] Akingbala JO, Oyewole BO, Uzo-Peters I, Karim OR, Baccus-Taylor GSH. Evaluating stored cassava quality in gari production. J Agric Environ 2005; 3: 75-80.

[38] Jonathan SG, Amos Tautau BMW, Olawuyi OJ. Food values, heavy metal accumulation, aflatoxin contamination and detection of exopolysacharrides in Lentinus Squar-rosulus Berk, a nigerian mushroom. Afr J Agric Res 2011; 6(13): 3007-12. 
[39] Iqbal SZ, Asi MR, Jinap S, Rashid U. Detection of aflatoxins and zearalenone contamination in wheat derived products. Food Control 2014; 35(1): 223-6

[http://dx.doi.org/10.1016/j.foodcont.2013.06.048]

[40] Kumar D, Kalita P. Reducing postharvest losses during storage of grain crops to strengthen food security in developing countries. Foods 2017; 6(1): 8 .

[http://dx.doi.org/10.3390/foods6010008] [PMID: 28231087]

[41] Tirado MC, Clarke R, Jaykus LA, McQuatters-Gollop A, Frank JM. Climate change and food safety: A review. Food Res Int 2010; 43(7): $1745-65$.

[http://dx.doi.org/10.1016/j.foodres.2010.07.003]

(C) 2018 El-Desouky et al.

This is an open access article distributed under the terms of the Creative Commons Attribution 4.0 International Public License (CC-BY 4.0), a copy of which is available at: (https://creativecommons.org/licenses/by/4.0/legalcode). This license permits unrestricted use, distribution, and reproduction in any medium, provided the original author and source are credited. 